\title{
Cholestane Glycosides from Solanum abutiloides. III
}

\author{
Hitoshi Yoshimitsu, ${ }^{*, a}$ Makiko NishidA, ${ }^{a}$ and Toshihiro NOHARA ${ }^{b}$ \\ Faculty of Engineering, Kyushu Kyoritsu University, ${ }^{a}$ 1-8 Jiyugaoka Yahata-nishi-ku, Kitakyushu 807-8585, Japan and \\ Faculty of Pharmaceutical Sciences, Kumamoto University, ${ }^{b}$ 5-1 Oe-honmachi, Kumamoto 862-0973, Japan. \\ Received August 26, 1999; accepted December 9, 1999
}

Four new cholestane glycosides, named abutilosides D (1), E (2), F (3) and G (4), were isolated from the fresh roots of Solanum abutiloides. By chemical and spectroscopic evidence, their structures were elucidated as 26-O- $\beta$ D-glucopyranosyl $3 \beta, 16 \alpha, 26$-trihydroxy-5 $\alpha$-cholestan-22-one $\quad 3-O$ - $\beta$-D-xylopyranosyl-(1 $\rightarrow 2)$ - $\alpha$-L-rhamnopyranosyl-(1 $\rightarrow 4)-\beta$-D-glucopyranoside and its desxylosyl compound (1 and 3 , respectively), 26- $O$ - $\beta$-D-glucopyranosyl $3 \beta, 16 \alpha, 26$-trihydroxycholest-5-en-22-one $\quad 3-O-\beta$-D-xylopyranosyl-(1 $\rightarrow 2)$ - $\alpha$-L-rhamnopyranosyl-(1 $\rightarrow 4)-\beta$-D-glucopyranoside and its desxylosyl compound ( 2 and 4 , respectively). These compounds were regarded as precursors of a dormantinone type compound on a hypothetical pathway of steroid biogenesis.

Key words cholestane glycoside; abutiloside; Solanum abutiloides; biogenesis

In the preceding paper, ${ }^{1)}$ we reported the isolation and structural determination of three cholestane glycosides, named abutilosides A, B and C (5), from the fresh roots of Solanum abutiloides. These compounds were important as a key intermediate in the biogenesis of steroidal alkaloids. In a continuing study on glycosidic constituents, we obtained four additional new cholestane glycosides, named abutilosides $D$ (1), E (2), F (3) and G (4). This paper describes their structural characterization.

The methanol extract of the fresh roots of Solanum abutiloides was partitioned into an AcOEt-water solvent system. MCI gel CHP-20P column chromatography of the water soluble portion provided the glycosidic constituents, which were purified by using a combination of Sephadex LH-20, silica gel and octadecyl silica gel (ODS) column chromatographies to furnish four abutilosides $(\mathbf{1}-\mathbf{4})$.

Abutiloside D (1) was obtained as a white powder, $[\alpha]_{\mathrm{D}}$ $-56.6^{\circ}(\mathrm{MeOH})$, and showed an ion peak due to $[\mathrm{M}-\mathrm{H}]^{-}$at $m / z 1035$ in the neg. FAB-MS. The ${ }^{1} \mathrm{H}-\mathrm{NMR}$ spectrum of 1 displayed two tertiary methyls at $\delta 0.67$ and 0.68 , three secondary methyls at $\delta 0.98(\mathrm{~d}, J=6.1 \mathrm{~Hz}), 1.19(\mathrm{~d}, J=6.7 \mathrm{~Hz})$ and $1.66(\mathrm{~d}, J=6.7 \mathrm{~Hz})$, and four anomeric protons at $\delta 4.82$ $(1 \mathrm{H}, \mathrm{d}, J=7.9 \mathrm{~Hz}), 4.98(1 \mathrm{H}, \mathrm{d}, J=7.3 \mathrm{~Hz}), 5.23(1 \mathrm{H}, \mathrm{d}, J=$ $7.9 \mathrm{~Hz})$ and $6.02\left(1 \mathrm{H}\right.$, br s). The above ${ }^{1} \mathrm{H}-\mathrm{NMR}$ spectrum of 1 was similar to that of abutiloside $\mathrm{C}(\mathbf{5})$. In the ${ }^{13} \mathrm{C}-\mathrm{NMR}$ spectrum of 1 , the signals due to the aglycone moiety, except for C-24, C-25 and C-26 at the side chain, and the sugar moiety were also in good agreement with those of 5 . Meanwhile, the neg. FAB-MS of 1 gave a quasi-molecular peak at $\mathrm{m} / \mathrm{z}$ 1035, which was higher by 162 mass units than that of 5 . Furthermore, a comparative study of the ${ }^{13} \mathrm{C}-\mathrm{NMR}$ spectrum of 1 with that of 5 indicated the presence of an additional glucosyl unit in 1, which was linked to the C-26 hydroxy group of an aglycone moiety. On acid hydrolysis, 1 afforded D-glucose, D-xylose and L-rhamnose, together with several unidentified artificial sapogenoles. ${ }^{2)}$ The ${ }^{1} \mathrm{H}$ - and ${ }^{13} \mathrm{C}-\mathrm{NMR}$ spectrum of 1 , which could be assigned with the aid of ${ }^{1} \mathrm{H}-$ ${ }^{1} \mathrm{H}$ correlation spectroscopy (COSY), heteronuclear multiple quantum coherence (HMQC), total correlation spectroscopy (TOCSY) and heteronuclear multiple bond correlation spectroscopy (HMBC) techniques, showed signals due to a tetrasaccharide moiety consisting of two glucopyranosyl moieties, one xylopyranosyl moiety and one rhamnopyra-

* To whom correspondence should be addressed. nosyl moiety. The HMBC experiment showed that the trisaccharide and monosaccharide moieties were linked to the C-3 and C-26 hydroxy groups of the aglycone, respectively. Moreover, the anomeric proton signals at $\delta 4.82,4.98,6.02$ and 5.23 showed long-range correlations with the ${ }^{13} \mathrm{C}$ signals at $\delta 75.1$ (C-26 of aglycone), 77.3 (C-3 of aglycone), 77.8 (C-4 of 4-substituted glucose) and 81.9 (C-2 of 2-substituted rhamnose), respectively. From the above evidence, the structure of 1 was concluded to be $26-O-\beta$-D-glucopyranosyl $3 \beta, 16 \alpha, 26$-trihydroxy-5 $\alpha$-cholestan-22-one 3-O- $\beta$-D-xylopyranosyl- $(1 \rightarrow 2)-\alpha$-L-rhamnopyranosyl- $(1 \rightarrow 4)-\beta$-D-glucopyranoside.

Abutiloside $\mathrm{E}(\mathbf{2})$ was obtained as a white powder, $[\alpha]_{\mathrm{D}}$ $-60.5^{\circ}(\mathrm{MeOH})$, and showed an ion peak due to $[\mathrm{M}-\mathrm{H}]^{-}$at $m / z 1033$, which was lower by 2 mass units than that of 1 , in the neg. FAB-MS. The ${ }^{1} \mathrm{H}-\mathrm{NMR}$ spectrum of 2 displayed two tertiary methyls at $\delta 0.70$ and 0.91 , three secondary methyls at $\delta 0.98(\mathrm{~d}, J=6.7 \mathrm{~Hz}), 1.20(\mathrm{~d}, J=6.7 \mathrm{~Hz})$ and $1.66(\mathrm{~d}$, $J=6.1 \mathrm{~Hz})$, an olefinic proton at $\delta 5.30(1 \mathrm{H}$, brs) and four anomeric protons at $\delta 4.81(1 \mathrm{H}, \mathrm{d}, J=7.9 \mathrm{~Hz}), 4.98(1 \mathrm{H}, \mathrm{d}$, $J=7.3 \mathrm{~Hz}), 5.23(1 \mathrm{H}, \mathrm{d}, J=7.9 \mathrm{~Hz})$ and $6.02(1 \mathrm{H}, \mathrm{br} \mathrm{s})$. Based on the above ${ }^{1} \mathrm{H}-\mathrm{NMR}$ data, the structure of 2 was considered to be analogous to that of 1 . In the ${ }^{13} \mathrm{C}-\mathrm{NMR}$ spectrum of 2 , the chemical shifts of the aglycone moiety, except for the signals owing to the $A$ and $B$ rings, and the sugar moiety showed coincidence with those of 1 . This evidence indicated the presence of a double bond in the $\mathrm{B}$ ring. In the HMBC experiment, the methyl proton signal at $\delta 0.91$ (H-19) showed long-range correlations with $\delta 140.9$ (C-5 of aglycone). Consequently, the structure of 2 was determined to be $26-O$ - $\beta$-D-glucopyranosyl $3 \beta, 16 \alpha, 26$-trihydroxycholest-5-en22-one 3-O- $\beta$-D-xylopyranosyl- $(1 \rightarrow 2)$ - $\alpha$-L-rhamnopyranosyl$(1 \rightarrow 4)$ - $\beta$-D-glucopyranoside.

Abutiloside $F(3)$ was obtained as a white powder, $[\alpha]_{D}$ $-51.8^{\circ}(\mathrm{MeOH})$, and showed an ion peak due to $[\mathrm{M}-\mathrm{H}]^{-}$at $m / z 903$, which was lower by 132 mass units than that of 1 , in the neg. FAB-MS. The ${ }^{1} \mathrm{H}-\mathrm{NMR}$ spectrum of 3 displayed two tertiary methyls at $\delta 0.68$ and 0.69 , three secondary methyls at $\delta 0.98(\mathrm{~d}, J=6.1 \mathrm{~Hz}), 1.19(\mathrm{~d}, J=6.7 \mathrm{~Hz})$ and $1.73(\mathrm{~d}, J=$ $6.1 \mathrm{~Hz})$, and three anomeric protons at $\delta 4.82(1 \mathrm{H}, \mathrm{d}, J=$ $7.9 \mathrm{~Hz}), 4.98(1 \mathrm{H}, \mathrm{d}, J=7.3 \mathrm{~Hz})$ and $5.90(1 \mathrm{H}, \mathrm{brs})$. In the ${ }^{13} \mathrm{C}$-NMR spectrum of 3 , signals due to the aglycone moiety were in good agreement with those of 1 , although the signals 
Table 1. 'H-NMR Chemical Shifts for Oligosaccharide Moieties of 1-4 (Pyridine- $d_{5}$ )

\begin{tabular}{|c|c|c|c|c|}
\hline & 1 & 2 & 3 & 4 \\
\hline \multicolumn{5}{|l|}{$3-O-$} \\
\hline Glc-1 & $4.98 \mathrm{~d}(7.3)$ & $4.98 \mathrm{~d}(7.3)$ & $4.98 \mathrm{~d}(7.3)$ & $4.98 \mathrm{~d}(7.3)$ \\
\hline Glc-2 & $3.99 \mathrm{dd}(7.3,9.1)$ & $3.99 \mathrm{dd}(8.5,8.5)$ & $4.01 \mathrm{dd}(7.3,9.1)$ & $4.00 \mathrm{dd}(7.3,9.1)$ \\
\hline Glc-3 & 4.22 & $4.22 \mathrm{dd}(8.5,8.5$ & $4.17 \mathrm{dd}(9.1,9.1)$ & $4.15 \mathrm{dd}(9.1,9.1)$ \\
\hline Glc-4 & $4.46 \mathrm{dd}(9.1,9.1)$ & $4.46 \mathrm{dd}(9.2,9.2)$ & $4.45 \mathrm{dd}(9.1,9.1)$ & $4.46 \mathrm{dd}(9.1,9.1)$ \\
\hline Glc-5 & $3.92 \mathrm{~m}$ & $3.87 \mathrm{~m}$ & $3.90 \mathrm{~m}$ & $3.87 \mathrm{~m}$ \\
\hline \multirow[t]{2}{*}{ Glc-6 } & $4.25 \mathrm{dd}(4.3,12.0)$ & 4.25 & $4.23 \mathrm{dd}(5.5,11.8)$ & $4.23 \mathrm{dd}(4.3,11.9)$ \\
\hline & $4.44 \mathrm{brd}(12.0)$ & 4.38 brd (12.0) & 4.35 brd (11.6) & $4.36 \mathrm{brd}(11.6)$ \\
\hline Rha-1 & $6.02 \mathrm{brs}$ & $6.02 \mathrm{brs}$ & $5.90 \mathrm{brs}$ & $5.90 \mathrm{brs}$ \\
\hline Rha-2 & 4.69 brd (3.0) & 4.68 brd (3.1) & $4.71 \mathrm{brs}$ & $4.71 \mathrm{brs}$ \\
\hline Rha-3 & $4.58 \mathrm{dd}(3.0,9.1)$ & $4.67 \mathrm{dd}(3.1,9.2)$ & 4.58 brd $(10.0)$ & 4.58 brd (10.4) \\
\hline Rha-4 & $4.27 \mathrm{dd}(9.1,9.1)$ & 4.27 & $4.37 \mathrm{dd}(9.1,9.1)$ & $4.39 \mathrm{dd}(9.1,9.1)$ \\
\hline Rha-5 & $5.02 \mathrm{~m}$ & 5.02 & $5.02 \mathrm{~m}$ & $5.01 \mathrm{~m}$ \\
\hline Rha-6 & $1.66 \mathrm{~d}(6.7)$ & $1.66 \mathrm{~d}(6.1)$ & $1.73 \mathrm{~d}(6.1)$ & $1.73 \mathrm{~d}(6.1)$ \\
\hline Xyl-1 & $5.23 \mathrm{~d}(7.9)$ & $5.23 \mathrm{~d}(7.9)$ & & \\
\hline Xyl-2 & $4.07 \mathrm{dd}(7.9,8.5)$ & $4.07 \mathrm{dd}(7.9,7.9)$ & & \\
\hline Xyl-3 & $4.12 \mathrm{dd}(8.5,8.5)$ & $4.12 \mathrm{dd}(8.5,8.5)$ & & \\
\hline Xyl-4 & 4.15 & $4.14 \mathrm{dd}(7.3,7.3)$ & & \\
\hline \multirow[t]{2}{*}{ Xyl-5 } & $3.67 \mathrm{dd}(10.4,10.4)$ & $3.66 \mathrm{dd}(9.8,10.6)$ & & \\
\hline & 4.29 & 4.28 & & \\
\hline \multicolumn{5}{|l|}{$26-O-$} \\
\hline Glc-1 & $4.82 \mathrm{~d}(7.9)$ & $4.81 \mathrm{~d}(7.9)$ & $4.82 \mathrm{~d}(7.9)$ & $4.82 \mathrm{~d}(7.9)$ \\
\hline Glc-2 & $4.02 \mathrm{dd}(7.9,8.5)$ & $4.02 \mathrm{dd}(7.9,8.5)$ & $4.02 \mathrm{dd}(7.9,8.5)$ & $4.01 \mathrm{dd}(7.9,8.5)$ \\
\hline Glc-3 & 4.25 & 4.25 & 4.26 & 4.26 \\
\hline Glc-4 & 4.25 & 4.25 & 4.26 & 4.26 \\
\hline Glc-5 & $3.94 \mathrm{~m}$ & $3.94 \mathrm{~m}$ & $3.92 \mathrm{~m}$ & $3.93 \mathrm{~m}$ \\
\hline \multirow[t]{2}{*}{ Glc-6 } & $4.39 \mathrm{br} \mathrm{d} \mathrm{(11.8)}$ & $4.39 \mathrm{dd}(5.5,11.6)$ & $4.33 \mathrm{brd}(11.2)$ & $4.34 \mathrm{br} \mathrm{d}(11.2)$ \\
\hline & $4.56 \mathrm{brd}(11.6)$ & $4.56 \mathrm{dd}(3.6,12.6)$ & $4.56 \mathrm{brd}(12.2)$ & $4.56 \mathrm{brd}(12.3)$ \\
\hline
\end{tabular}

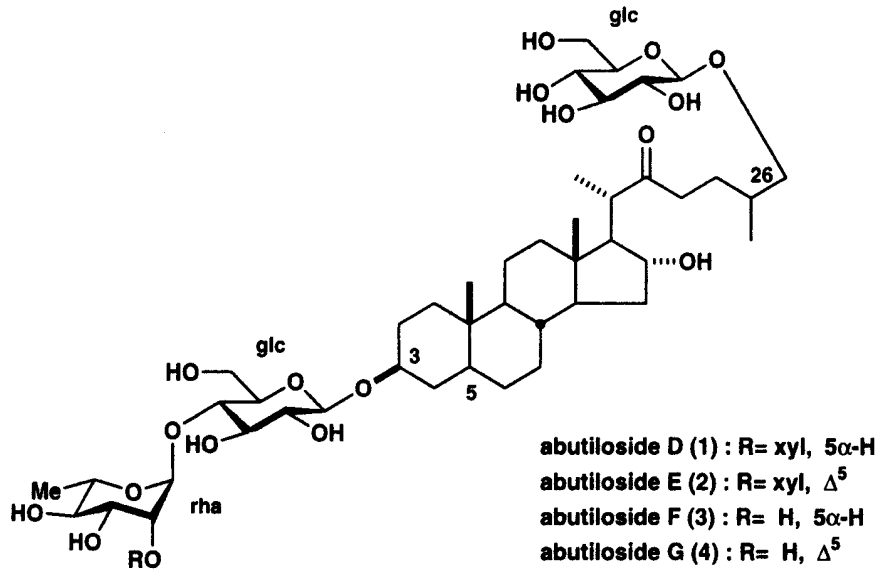

due to the sugar moiety were not identical. On acid hydrolysis, 3 afforded D-glucose and L-rhamnose, together with several unidentified artificial sapogenoles. ${ }^{2)}$ The ${ }^{1} \mathrm{H}-$ and ${ }^{13} \mathrm{C}$ NMR data of the sugar moiety were assigned by ${ }^{1} \mathrm{H}-{ }^{1} \mathrm{H}$ COSY and HMQC techniques. In the HMBC experiment, long-range correlations were observed between the anomeric proton [ $\delta 4.82(\mathrm{~d}, J=7.9 \mathrm{~Hz})$ ] of terminal glucose and the C$26(\delta 75.1)$ of aglycone, the anomeric proton $[\delta 4.98(\mathrm{~d}$, $J=7.3 \mathrm{~Hz})]$ of 4-substituted glucose and the C-3 $(\delta 77.4)$ of aglycone and the anomeric proton [ $\delta 5.90(\mathrm{brs})]$ of terminal rhamnose and the $\mathrm{C}-4(\delta$ 78.5) of 4-substituted glucose. Based on the above evidence, the structure of $\mathbf{3}$ was elucidated as a cholestane glycoside with a terminal xylose absent from 1.

Abutiloside G (4) was obtained as a white powder, $[\alpha]_{D}$
$-81.3^{\circ}(\mathrm{MeOH})$, and showed an ion peak due to $[\mathrm{M}-\mathrm{H}]^{-}$at $\mathrm{m} / \mathrm{z} 901$, which was lower by 2 mass units than that of 3 , in the neg. FAB-MS. In the ${ }^{1} \mathrm{H}-$ and ${ }^{13} \mathrm{C}-\mathrm{NMR}$ spectrum of 4 , signals due to an aglycone moiety were consistent with those of 2 , while signals due to a sugar moiety were almost superimposable on those of 3 . From the above evidence, the structure of 4 was concluded to have a double bond at the C-5 of 3. The configuration at $\mathrm{C}-25$ in $1-4$ was deduced to be $R$ due to the coexistence of dioscin and solamargine in this plant. However, this presumption was a moot point.

Kaneko et al. presented a hypothetical biogenetic pathway of solanidine in Veratrum. ${ }^{3)} 1-4$ were regarded as precursors of a dormantinone type compound on a hypothetical pathway of steroid biogenesis. Further, 2 and 4 were corresponding 5ene compounds to 1 and 3 . Consequently, the coexistence of a 5-ene type compound was confirmed in the roots of Solanum abutiloides.

\section{Experimental}

Optical rotations were taken with a JASCO DIP-1000 automatic digital polarimeter. The ${ }^{1} \mathrm{H}$ - and ${ }^{13} \mathrm{C}-\mathrm{NMR}$ spectra were measured with a JEOL alpha 500 NMR spectrometer and chemical shifts are given on a $\delta(\mathrm{ppm})$ scale with tetramethylsilane (TMS) as an internal standard. The FAB-MS was measured with a JEOL DX-303 HF spectrometer and taken in a 3-nitrobenzyl alcohol matrix. HPLC was carried out using a TSK gel-120T $(7.8 \mathrm{~mm}$ i.d. $\times 30 \mathrm{~cm})$ column with a Tosoh CCPM pump and Tosoh RI8010 differential refractometer as a detector. TLC was performed on precoated Kieselgel $60 \mathrm{~F}_{245}$ (Merck), and detection was achieved by spraying them with $10 \% \mathrm{H}_{2} \mathrm{SO}_{4}$ followed by heating. Column chromatography was carried out on Kieselgel (230-400 mesh, Merck), Sephadex LH-20 (Pharmacia), ODS (PrePAK-500/C 18 , Waters) and MCI gel CHP-20P (Mitsubishi Chemical Ind.)

Extraction and Separation The seeds identified as Solanum abutiloides at the National Research Institute of Vegetables, Ministry of Agri- 
Table 2. ${ }^{13} \mathrm{C}-\mathrm{NMR}$ Data for $\mathbf{1}-\mathbf{5}$ (Pyridine- $\left.d_{5}\right)$

\begin{tabular}{|c|c|c|c|c|c|}
\hline & 1 & 2 & 3 & 4 & 5 \\
\hline C- 1 & 37.1 & 37.3 & 37.1 & 37.4 & 37.0 \\
\hline C- 2 & 29.9 & 30.2 & 30.0 & 30.2 & 29.9 \\
\hline C- 3 & 77.3 & 78.2 & 77.4 & 78.4 & 77.3 \\
\hline C- 4 & 34.8 & 39.3 & 34.9 & 39.3 & 34.8 \\
\hline C- 5 & 44.6 & 140.9 & 44.6 & 140.9 & 44.5 \\
\hline C- 6 & 28.9 & 121.8 & 28.9 & 121.8 & 28.9 \\
\hline C- 7 & 32.2 & 32.1 & 32.4 & 32.1 & 32.2 \\
\hline C- 8 & 35.1 & 31.6 & 35.1 & 31.8 & 35.1 \\
\hline C- 9 & 54.4 & 50.3 & 54.4 & 50.3 & 54.4 \\
\hline C- 10 & 35.7 & 36.9 & 35.7 & 36.9 & 35.7 \\
\hline C-11 & 21.1 & 20.9 & 21.1 & 20.9 & 21.0 \\
\hline C-12 & 40.2 & 39.9 & 40.2 & 39.9 & 40.1 \\
\hline C-13 & 44.4 & 44.1 & 44.4 & 44.1 & 44.4 \\
\hline C-14 & 53.7 & 53.9 & 53.7 & 53.9 & 53.7 \\
\hline C-15 & 37.0 & 37.0 & 37.0 & 37.0 & 36.9 \\
\hline C-16 & 75.9 & 75.9 & 75.9 & 75.9 & 75.9 \\
\hline C-17 & 63.4 & 63.3 & 63.4 & 63.3 & 63.4 \\
\hline C-18 & 13.7 & 13.4 & 13.7 & 13.4 & 13.7 \\
\hline C-19 & 12.3 & 19.4 & 12.3 & 19.4 & 12.3 \\
\hline C-20 & 49.3 & 49.3 & 49.3 & 49.3 & 49.3 \\
\hline C-21 & 16.8 & 16.8 & 16.8 & 16.8 & 16.8 \\
\hline C-22 & 214.9 & 214.8 & 214.9 & 214.8 & 215.0 \\
\hline C-23 & 39.0 & 39.0 & 39.0 & 39.0 & 39.1 \\
\hline C-24 & 28.0 & 28.0 & 28.0 & 28.0 & 27.9 \\
\hline C-25 & 33.4 & 33.4 & 33.4 & 33.4 & 36.1 \\
\hline $\mathrm{C}-26$ & 75.1 & 75.1 & 75.1 & 75.1 & 67.3 \\
\hline C-27 & 17.6 & 17.6 & 17.5 & 17.6 & 17.3 \\
\hline \multicolumn{6}{|l|}{$3-\mathrm{O}$} \\
\hline Glc-1 & 102.0 & 102.4 & 102.8 & 102.7 & 102.0 \\
\hline Glc-2 & 75.6 & 75.6 & 75.5 & 75.5 & 75.5 \\
\hline Glc-3 & 76.6 & 76.6 & 76.8 & 76.7 & 76.6 \\
\hline Glc-4 & 77.8 & 77.7 & 78.5 & 78.2 & 77.8 \\
\hline Glc-5 & 77.4 & 77.3 & 77.2 & 77.2 & 77.3 \\
\hline Glc-6 & 61.7 & 61.7 & 61.7 & 61.6 & 61.7 \\
\hline Rha-1 & 101.2 & 101.2 & 102.1 & 101.5 & 101.2 \\
\hline Rha-2 & 81.9 & 81.9 & 72.6 & 72.6 & 81.9 \\
\hline Rha-3 & 72.9 & 72.9 & 72.8 & 72.8 & 72.8 \\
\hline Rha-4 & 74.4 & 74.4 & 74.0 & 74.0 & 74.4 \\
\hline Rha-5 & 70.0 & 70.0 & 70.4 & 70.4 & 69.9 \\
\hline Rha-6 & 18.4 & 18.4 & 18.5 & 18.5 & 18.4 \\
\hline Xyl-1 & 107.6 & 107.6 & & & 107.5 \\
\hline Xyl-2 & 75.2 & 75.2 & & & 75.5 \\
\hline Xyl-3 & 78.5 & 78.5 & & & 78.4 \\
\hline Xyl-4 & 71.0 & 71.0 & & & 71.0 \\
\hline Xyl-5 & 67.4 & 67.4 & & & 67.4 \\
\hline \multicolumn{6}{|l|}{ 26-O- } \\
\hline Glc-1 & 104.9 & 104.9 & 104.9 & 104.9 & \\
\hline Glc-2 & 75.2 & 75.2 & 75.2 & 75.3 & \\
\hline Glc-3 & 78.5 & 78.5 & 78.5 & 78.5 & \\
\hline Glc-4 & 71.7 & 71.7 & 71.7 & 71.7 & \\
\hline Glc-5 & 78.6 & 78.6 & 78.6 & 78.6 & \\
\hline Glc-6 & 62.8 & 62.8 & 62.8 & 62.8 & \\
\hline
\end{tabular}

culture, Forestry and Fisheries, Ano, Mie in Japan, were cultivated at the Botanical Garden of Kumamoto University. The harvested roots $(2.24 \mathrm{~kg})$ of this plant were extracted with $\mathrm{MeOH}$, and the extract was partitioned in AcOEt and water $(1: 1, \mathrm{v} / \mathrm{v})$. The water soluble portion $(87.6 \mathrm{~g})$ was subjected to $\mathrm{MCI}$ gel CHP-20P column chromatography with $\mathrm{MeOH}-\mathrm{H}_{2} \mathrm{O}$ $(20 \rightarrow 30 \rightarrow 40 \rightarrow 50 \rightarrow 60 \rightarrow 70 \rightarrow 80 \rightarrow 90 \rightarrow 100 \%)$ to afford ten fractions (fr. $1-$ fr.10). Fraction $3(1.04 \mathrm{~g})$ was further separated by ODS column chromatography with $\mathrm{MeOH}-\mathrm{H}_{2} \mathrm{O}(40 \rightarrow 50 \rightarrow 60 \rightarrow 70 \%)$ and silica gel column chromatography with $\mathrm{CHCl}_{3}-\mathrm{MeOH}-\mathrm{H}_{2} \mathrm{O}(6: 4: 0.5$, v/v), followed by HPLC with $\mathrm{MeOH}-\mathrm{H}_{2} \mathrm{O}(3: 2)$, to furnish abutilosides D (1) $(423 \mathrm{mg})$ and $\mathrm{E}(2)$ $(27 \mathrm{mg})$. Fraction $4(1.67 \mathrm{~g})$ was subjected to ODS column chromatography with $\mathrm{MeOH}-\mathrm{H}_{2} \mathrm{O}(40 \rightarrow 50 \rightarrow 60 \rightarrow 70 \rightarrow 80 \%)$ to afford two fractions (fr.11- fr.12). Fraction 11 was further separated by Sephadex LH-20 column chromatography with $\mathrm{MeOH}$ and silica gel column chromatography with $\mathrm{CHCl}_{3}-\mathrm{MeOH}-\mathrm{H}_{2} \mathrm{O}\left(6: 4: 0.5\right.$, v/v), followed by HPLC with $\mathrm{MeOH}-\mathrm{H}_{2} \mathrm{O}$ (3:2), to furnish abutiloside $\mathrm{G}(4)(72 \mathrm{mg})$. Fraction 12 was further separated by Sephadex LH-20 column chromatography with $\mathrm{MeOH}$ and silica gel column chromatography with $\mathrm{CHCl}_{3}-\mathrm{MeOH}-\mathrm{H}_{2} \mathrm{O}(6: 4: 0.5$, v/v), followed by HPLC with $\mathrm{MeOH}-\mathrm{H}_{2} \mathrm{O}(3: 2)$, to furnish abutiloside $\mathrm{F}$ (3) (229 mg).

Abutiloside D (1) A white powder, $[\alpha]_{\mathrm{D}}^{25}-56.6^{\circ}(c=0.80, \mathrm{MeOH})$. Neg. FAB-MS $(m / z): 1035[\mathrm{M}-\mathrm{H}]^{-} .{ }^{1} \mathrm{H}-\mathrm{NMR}$ (pyridine- $\left.d_{5}\right) \delta: 0.67(3 \mathrm{H}, \mathrm{s}$, H-19), 0.68 (3H, s, H-18), 0.98 (3H, d, $J=6.1 \mathrm{~Hz}, \mathrm{H}-27), 1.19$ (3H, d, $J=$ $6.7 \mathrm{~Hz}, \mathrm{H}-21$ ), 3.61 (1H, dd, $J=6.7,8.7 \mathrm{~Hz}, \mathrm{H}-26 \mathrm{a}), 3.87$ (1H, m, H-3), 3.95 (1H, dd, $J=6.7,9.1 \mathrm{~Hz}, \mathrm{H}-26 \mathrm{~b}), 4.24(1 \mathrm{H}, \mathrm{H}-16)$. Signals for the saccharide moiety are shown in Table $1 .{ }^{13} \mathrm{C}-\mathrm{NMR}$ (pyridine- $d_{5}$ ): Table 2.

Abutiloside E (2) A white powder, $[\alpha]_{\mathrm{D}}^{25}-60.5^{\circ}(c=0.35, \mathrm{MeOH})$. Neg. FAB-MS $(m / z): 1033[\mathrm{M}-\mathrm{H}]^{-} .{ }^{1} \mathrm{H}-\mathrm{NMR}$ (pyridine- $\left.d_{5}\right) \delta: 0.70(3 \mathrm{H}, \mathrm{s}$, $\mathrm{H}-18), 0.91$ (3H, s, H-19), $0.98(3 \mathrm{H}, \mathrm{d}, J=6.7 \mathrm{~Hz}, \mathrm{H}-27), 1.20$ (3H, d, $J=$ $6.7 \mathrm{~Hz}, \mathrm{H}-21), 3.60$ (1H, dd, $J=5.9,9.2 \mathrm{~Hz}, \mathrm{H}-26 \mathrm{a}), 3.82(1 \mathrm{H}, \mathrm{m}, \mathrm{H}-3), 3.96$ (1H, H-26b), 4.23 (1H, H-16), 5.30 (1H, br s, H-6). Signals for the saccharide moiety are shown in Table $1 .{ }^{13} \mathrm{C}-\mathrm{NMR}$ (pyridine- $d_{5}$ ): Table 2.

Abutiloside F (3) A white powder, $[\alpha]_{\mathrm{D}}^{25}-51.8^{\circ}(c=0.75, \mathrm{MeOH})$. Neg. FAB-MS $(m / z): 903[\mathrm{M}-\mathrm{H}]^{-} .{ }^{1} \mathrm{H}-\mathrm{NMR}$ (pyridine- $\left.d_{5}\right) \delta: 0.68(3 \mathrm{H}, \mathrm{s}$, $\mathrm{H}-19), 0.69$ (3H, s, H-18), 0.98 (3H, d, $J=6.1 \mathrm{~Hz}, \mathrm{H}-27), 1.19$ (3H, d, $J=$ $6.7 \mathrm{~Hz}, \mathrm{H}-21), 3.61$ (1H, dd, $J=6.1,9.2 \mathrm{~Hz}, \mathrm{H}-26 \mathrm{a}), 3.81(1 \mathrm{H}, \mathrm{m}, \mathrm{H}-3), 3.95$ $(1 \mathrm{H}, \mathrm{dd}, J=6.1,9.2 \mathrm{~Hz}, \mathrm{H}-26 \mathrm{~b}), 4.24$ (1H, H-16). Signals for the saccharide moiety are shown in Table $1 .{ }^{13} \mathrm{C}$-NMR (pyridine- $d_{5}$ ): Table 2.

Abutiloside G (4) A white powder, $[\alpha]_{\mathrm{D}}^{25}-81.3^{\circ}(c=0.75, \mathrm{MeOH})$. Neg. FAB-MS $(m / z): 901[\mathrm{M}-\mathrm{H}]^{-} .{ }^{1} \mathrm{H}-\mathrm{NMR}$ (pyridine- $\left.d_{5}\right) \delta: 0.71(3 \mathrm{H}, \mathrm{s}$, H-18), 0.92 (3H, s, H-19), 0.98 (3H, d, $J=6.1 \mathrm{~Hz}, \mathrm{H}-27), 1.20$ (3H, d, $J=$ $6.1 \mathrm{~Hz}, \mathrm{H}-21), 3.61$ (1H, dd, $J=6.7,9.8 \mathrm{~Hz}, \mathrm{H}-26 \mathrm{a}), 3.74(1 \mathrm{H}, \mathrm{m}, \mathrm{H}-3), 3.95$ (1H, dd, $J=6.1,9.8, \mathrm{H}-26 \mathrm{~b}), 4.24$ (1H, H-16), 5.31 (1H, br s, H-6). Signals for the saccharide moiety are shown in Table $1 .{ }^{13} \mathrm{C}-\mathrm{NMR}$ (pyridine- $d_{5}$ ): Table 2.

Sugars Analysis of 1 and 3 A solution of each of 1 and $3(2 \mathrm{mg})$ in $2 \mathrm{~N}$ $\mathrm{HCl}$-dioxane $(1: 1,2 \mathrm{ml})$ was heated at $100^{\circ} \mathrm{C}$ for $1 \mathrm{~h}$. The reaction mixture was diluted with $\mathrm{H}_{2} \mathrm{O}$ and evaporated to remove dioxane. The solution was neutralized with Amberlite MB-3 and passed through a SEP-PAK $\mathrm{C}_{18}$ cartridge to give a sugar fraction. A solution of sugar fraction analyzed by TLC $\left[\mathrm{CH}_{3} \mathrm{CN}-\mathrm{MeOH}-\mathrm{H}_{2} \mathrm{O}(6: 4: 1), 1\right.$ : rhamnose, $R f 0.54$; xylose, $R f 0.40$; glucose, $R f 0.29$; 3: rhamnose, $R f 0.54$; glucose, $R f 0.29$ ]. A solution of the sugar fraction in $1 \mathrm{ml}$ of $\mathrm{H}_{2} \mathrm{O}$ was treated with a solution of $\mathrm{L}-(-)-\alpha$-methylbenzylamine $(150 \mu \mathrm{l})$ and $\mathrm{NaBH}_{3} \mathrm{CN}(8 \mathrm{mg})$ in $1 \mathrm{ml}$ of $\mathrm{EtOH}$, and the mixture was kept at $40^{\circ} \mathrm{C}$ for $3 \mathrm{~h}$. Then, several drops of acetic acid were added and the mixture was concentrated to dryness. The residue dissolved in $\mathrm{Ac}_{2} \mathrm{O}-\mathrm{C}_{5} \mathrm{H}_{5} \mathrm{~N}(1: 1,2 \mathrm{ml})$ was treated with 4-(dimethylamino)pyridine (DMAP) $(20 \mathrm{mg})$, and the whole mixture was left at room temperature overnight. After the removal of excess $\mathrm{Ac}_{2} \mathrm{O}$ and $\mathrm{C}_{5} \mathrm{H}_{5} \mathrm{~N}$, the residue dissolved in $20 \% \mathrm{CH}_{3} \mathrm{CN}$ was loaded into a SEP-PAK $\mathrm{C}_{18}$ cartridge and eluted with $20 \% \mathrm{CH}_{3} \mathrm{CN}$ (total $7 \mathrm{ml}$ ) and $100 \% \mathrm{CH}_{3} \mathrm{CN}$. The fraction eluted with $100 \% \mathrm{CH}_{3} \mathrm{CN}$ was analyzed by normal-phase HPLC. Conditions of HPLC: column, Develosil $60-3,3 \mu \mathrm{m}(4.6 \mathrm{~mm}$ i.d. $\times 150 \mathrm{~mm})$; solvent, $n$-hexaneEtOH (19:1); flow rate, $1.20 \mathrm{ml} / \mathrm{min}$; detection, UV $(230 \mathrm{~nm}) . t_{\mathrm{R}}(\mathrm{min})$ of 1 ( $N$-acetyl-L- $\alpha$-methylbenzylamino)-1-deoxyalditol acetates were as follows. 1: L-rhamnose 17.2, D-xylose 30.8, D-glucose 30.8 (reference: L-rhamnose 17.0, D-xylose 30.7, D-glucose 30.8). 3: L-rhamnose 17.2, D-glucose 30.7.

Acknowledgment We are grateful to Mr. I. Hori and Mr. K. Kitaoka of our faculty for cultivating the crude plants in the Botanical Garden, and to Mr. K. Takeda and Mr. T. Iriguti of Kumamoto University for measurement of the mass and NMR spectra.

\section{References}

1) a) Ohmura H., Nakamura T., Tian R.-H., Yahara S., Yoshimitsu H., Nohara T., Tetrahedron Lett., 36, 8443-8444 (1995); b) Tian R.-H., Ohmura O., Yoshimitsu H., Nohara T., Matsui M., Chem. Pharm. Bull., 44, 1119-1121 (1996).

2) Oshima R., Yamauchi Y., Kumanotani J., Carbohydr. Res., 107, 169176 (1982).

3) Kaneko K., Tanaka W., Mitsuhashi H., Phytochemistry, 15, 13911393 (1976). 